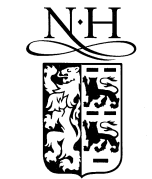

ELSEVIER

\title{
New non-fatigue ferroelectric thin films of barium bismuth tantalate
}

\author{
Chung-Hsin Lu *, Cheng-Yen Wen \\ Department of Chemical Engineering, National Taiwan University, Taipei, Taiwan \\ Received 5 August 1998; accepted 11 August 1998
}

\begin{abstract}
New non-fatigue ferroelectric thin films of barium bismuth tantalate $\left(\mathrm{BaBi}_{2} \mathrm{Ta}_{2} \mathrm{O}_{9}\right)$ were synthesized in this work. These films were prepared on $\mathrm{Pt} / \mathrm{Ti} / \mathrm{SiO}_{2} / \mathrm{Si}$ substrates by the metalorganic decomposition method. As-deposited films were amorphous, and became well-crystallized after annealing at $700^{\circ} \mathrm{C}$. The annealed films exhibited fairly smooth surface and small grain size (around $10 \mathrm{~nm}$ ). The measured dielectric constant and dissipation factor of $\mathrm{BaBi}_{2} \mathrm{Ta}_{2} \mathrm{O}_{9}$ films at $10 \mathrm{kHz}$ were 97.7 and 0.0257 , respectively. The polarization-electric field hysteresis loops revealed the ferroelectric characteristics of $\mathrm{BaBi}_{2} \mathrm{Ta}_{2} \mathrm{O}_{9}$ films. Furthermore, the fatigue test indicated that these films hardly degraded in the polarization after $10^{9}$ switching cycles. Because of its ferroelectric properties and excellent fatigue resistance, $\mathrm{BaBi}_{2} \mathrm{Ta}_{2} \mathrm{O}_{9}$ has great potential in becoming a new candidate material for the applications of ferroelectric random access memories. (C) 1999 Elsevier Science B.V. All rights reserved.
\end{abstract}

PACS: 77.55. +f; 77.80.- e; 77.84. - y; 77.80.Fm

Keywords: Ferroelectric; Thin film; Barium bismuth tantalate $\left(\mathrm{BaBi}_{2} \mathrm{Ta}_{2} \mathrm{O}_{9}\right)$; Dielectric properties; Excellent switching behavior

\section{Introduction}

Ferroelectric materials have attracted much attention for the applications to non-volatile random access memories [1]. Among these materials, $\mathrm{Pb}(\mathrm{Zr}, \mathrm{Ti}) \mathrm{O}_{3}$ has been intensively investigated for more than a decade. Although $\mathrm{Pb}(\mathrm{Zr}, \mathrm{Ti}) \mathrm{O}_{3}$ exhibits excellent ferroelectric properties, $\mathrm{Pb}(\mathrm{Zr}, \mathrm{Ti}) \mathrm{O}_{3}$ thin films fabricated on metal electrodes suffer serious degradation of remnant polarization after long-term switching cycles [2]. Various models concerning the mechanisms for the loss of polarization have been

\footnotetext{
* Corresponding author. Fax: + 886-2-362-3040
}

proposed [3-5]. Oxygen vacancies are considered to be the main cause for such fatigue phenomenon. On the other hand, bismuth-layered perovskite $\mathrm{SrBi}_{2} \mathrm{Ta}_{2} \mathrm{O}_{9}$ thin films have been reported to be a potential candidate for non-volatile random access memories, since these films exhibit good polarization hysteresis behavior and fatigue-free (up to $10^{12}$ switching cycles) characteristics [6]. A lot of efforts have been devoted to integrate these materials for the application of VLSI [7-9]. These studies show that $\mathrm{SrBi}_{2} \mathrm{Ta}_{2} \mathrm{O}_{9}$ exhibits low leakage current density, long data retention time, and stable imprint characteristics. Furthermore, $\mathrm{SrBi}_{2} \mathrm{Ta}_{2} \mathrm{O}_{9}$ thin films have superior fatigue resistance compared to $\mathrm{Pb}(\mathrm{Zr}, \mathrm{Ti}) \mathrm{O}_{3}$ films. 
Although the preparation and properties of $\mathrm{SrBi}_{2} \mathrm{Ta}_{2} \mathrm{O}_{9}$ films have been thoroughly studied, a similar compound $\mathrm{BaBi}_{2} \mathrm{Ta}_{2} \mathrm{O}_{9}$ has not been investigated in detail. It was reported that $\mathrm{BaBi}_{2} \mathrm{Ta}_{2} \mathrm{O}_{9}$ thin films showed low leakage current and had good dielectric properties for the use in conventional circuits [10]. In the ceramic form, $\mathrm{BaBi}_{2} \mathrm{Ta}_{2} \mathrm{O}_{9}$ possesses a lower Curie temperature, and a higher dielectric constant than does $\mathrm{SrBi}_{2} \mathrm{Ta}_{2} \mathrm{O}_{9}$ at room temperature [11]. We have investigated the formation mechanism and thermal stability of $\mathrm{BaBi}_{2} \mathrm{Ta}_{2} \mathrm{O}_{9}$ ceramics, and proposed a new process different from the traditional solid-state reaction to prepare welldensified $\mathrm{BaBi}_{2} \mathrm{Ta}_{2} \mathrm{O}_{9}$ ceramics [12]. On the other hand, the studies concerning the $\mathrm{BaBi}_{2} \mathrm{Ta}_{2} \mathrm{O}_{9}$ thin films are few. In this study, we used MOD (metalorganic decomposition) method to synthesize $\mathrm{BaBi}_{2} \mathrm{Ta}_{2} \mathrm{O}_{9}$ thin films on $\mathrm{Pt} / \mathrm{Ti} / \mathrm{SiO}_{2} / \mathrm{Si}$ substrates. The phase evolution of $\mathrm{BaBi}_{2} \mathrm{Ta}_{2} \mathrm{O}_{9}$ thin films during annealing processes was examined. The microstructures of the prepared films were observed by scanning electron microscopy (SEM) and atomic force microscopy (AFM). Furthermore, the dielectric and ferroelectric properties of $\mathrm{BaBi}_{2} \mathrm{Ta}_{2} \mathrm{O}_{9}$ films were investigated, including remnant polarization, coercive field, and fatigue endurance.

\section{Experimental}

Barium 2-ethylhexanoate, bismuth 2-ethylhexanoate, and tantalum ethoxide were used as the starting materials, and toluene as the solvent. The solutions were thoroughly mixed according to the stoichiometric ratio, then the prepared precursor was spin-coated onto $\mathrm{Pt} / \mathrm{Ti} / \mathrm{SiO}_{2} / \mathrm{Si}$ substrates. The spin-coated films were heated on a hot plate at $150^{\circ} \mathrm{C}$ to remove residual toluene solvent and were subsequently pyrolyzed at $400^{\circ} \mathrm{C}$. The pyrolyzed films were annealed at $500-800^{\circ} \mathrm{C}$ in the flowing oxygen for $2 \mathrm{~h}$. The thickness of prepared $\mathrm{BaBi}_{2} \mathrm{Ta}_{2} \mathrm{O}_{9}$ thin films was approximately $0.4 \mu \mathrm{m}$. Phase identification was performed using X-ray diffraction (XRD). The surface morphology was observed by SEM and AFM using a tapping mode with amplitude modulation. The dielectric properties were measured on metal-ferroelectric-metal capacitors using an impedance analyzer. A standard ferroelec- tricity analyzer was employed to detect the ferroelectric characteristics.

\section{Results and discussion}

Fig. 1 shows the XRD patterns of $\mathrm{BaBi}_{2} \mathrm{Ta}_{2} \mathrm{O}_{9}$ thin films deposited on $\mathrm{Pt} / \mathrm{Ti} / \mathrm{SiO}_{2} / \mathrm{Si}$ substrates at various annealing temperatures. At $500^{\circ} \mathrm{C}$ the film remains amorphous as shown in Fig. 1a. From $600^{\circ} \mathrm{C}$ (see Fig. 1b), $\mathrm{BaBi}_{2} \mathrm{Ta}_{2} \mathrm{O}_{9}$ phase starts to form and the (105) diffraction peak appears at around $2 \theta=28^{\circ}$. However, the rather broad peak indicates that this film is not fully crystallized. The crystallization of $\mathrm{BaBi}_{2} \mathrm{Ta}_{2} \mathrm{O}_{9}$ films gradually progresses with increasing temperature. At $700^{\circ} \mathrm{C}$ the crystallization of $\mathrm{BaBi}_{2} \mathrm{Ta}_{2} \mathrm{O}_{9}$ thin films is further enhanced, and the diffraction peaks of $\mathrm{BaBi}_{2} \mathrm{Ta}_{2} \mathrm{O}_{9}$ are clearly observed (see Fig. 1d), indicating that $\mathrm{BaBi}_{2} \mathrm{Ta}_{2} \mathrm{O}_{9}$ thin film is well-crystallized. The diffraction peaks in Fig. 1d are well in consistence with those of $\mathrm{BaBi}_{2} \mathrm{Ta}_{2} \mathrm{O}_{9}$ ceramics reported [12]. Therefore, it is confirmed that the $\mathrm{BaBi}_{2} \mathrm{Ta}_{2} \mathrm{O}_{9}$ single phase was obtained. It is noted that no intermediate phase is found within the temperature range of $500-700^{\circ} \mathrm{C}$.

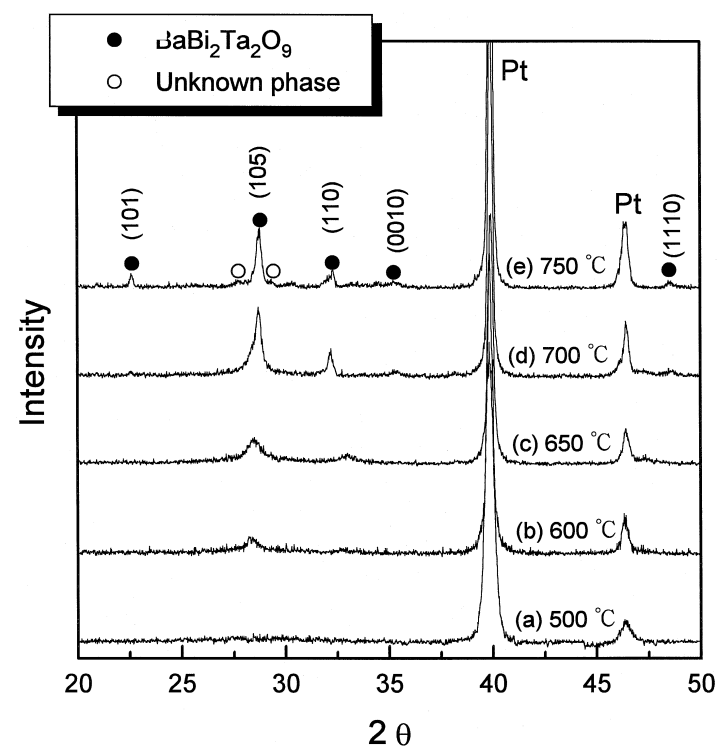

Fig. 1. XRD patterns of $\mathrm{BaBi}_{2} \mathrm{Ta}_{2} \mathrm{O}_{9}$ thin films deposited on $\mathrm{Pt} / \mathrm{Ti} / \mathrm{SiO}_{2} / \mathrm{Si}$ substrates after annealing at (a) 500, (b) 600, (c) 650, (d) 700 and (e) $750^{\circ} \mathrm{C}$. 
Apparently, the crystallized $\mathrm{BaBi}_{2} \mathrm{Ta}_{2} \mathrm{O}_{9}$ thin films are nucleated and grown directly from the amorphous phase. The lattice constants of $\mathrm{BaBi}_{2} \mathrm{Ta}_{2} \mathrm{O}_{9}$ thin film are calculated from the $d$-spacings of peaks (101), (105), (110), and (0010). Assuming that the crystal system of the $\mathrm{BaBi}_{2} \mathrm{Ta}_{2} \mathrm{O}_{9}$ thin film is pseudo-tetragonal, the lattice constants are deter- mined to be $a=0.3942 \mathrm{~nm}$, and $c=0.2542 \mathrm{~nm}$. On the other hand, a tiny amount of an unknown phase appears after $750^{\circ} \mathrm{C}$ annealing, as shown in Fig. 1e. This phase is probably formed from the interaction between films and substrates.

Fig. 2a shows the scanning electron microscopic image of the $\mathrm{BaBi}_{2} \mathrm{Ta}_{2} \mathrm{O}_{9}$ thin film annealed at

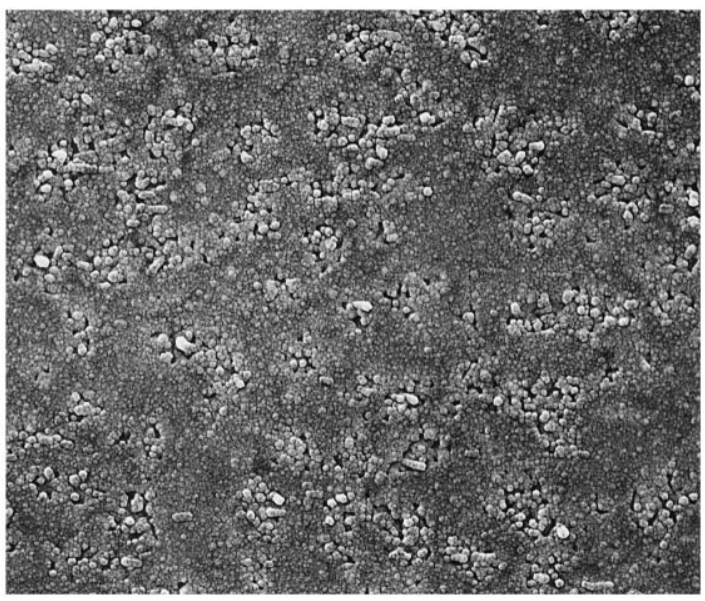

(a)

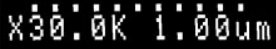

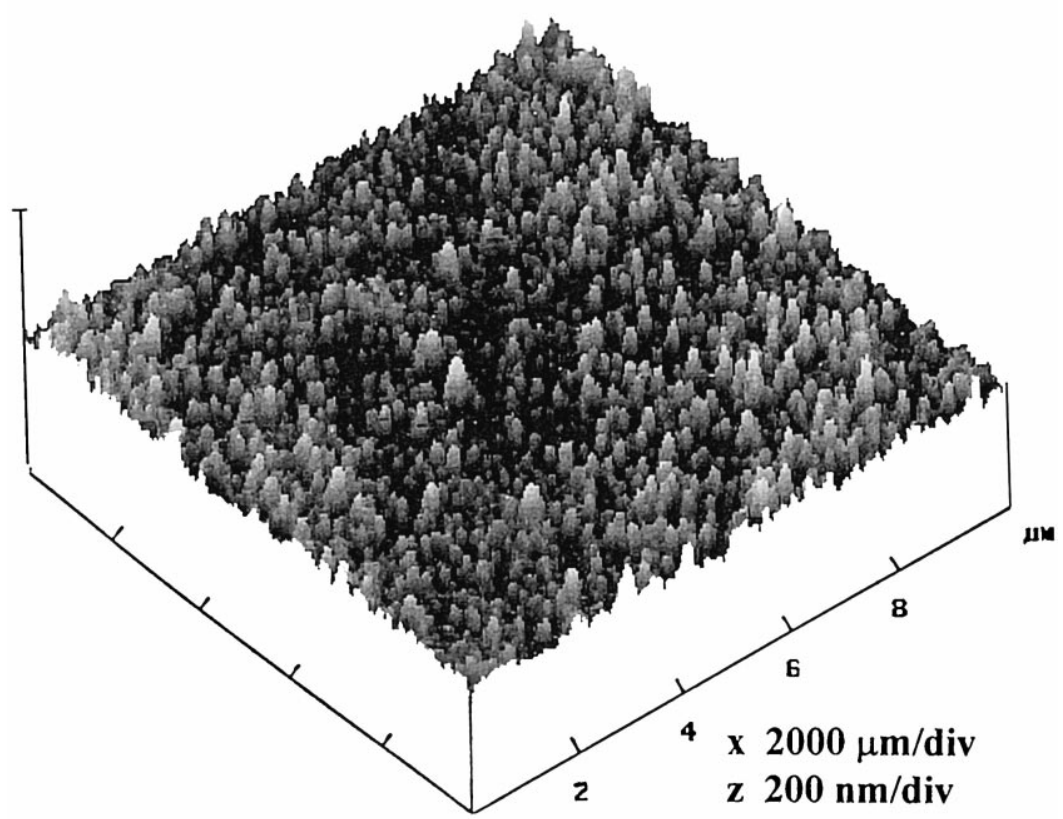

(b)

Fig. 2. (a) Scanning electron micrograph and (b) atomic force micrograph of $\mathrm{BaBi}_{2} \mathrm{Ta}_{2} \mathrm{O}_{9}$ thin films annealed at $700^{\circ} \mathrm{C}$. 
$700^{\circ} \mathrm{C}$. It is found that the grains of this film have a spherical shape with small grain size, and the surface of this film seems dense and flat. Fig. 2b demonstrates the surface morphology of the same film observed by an atomic force microscope with scanning area of $10 \mu \mathrm{m} \times 10 \mu \mathrm{m}$. This image indicates that the surface of $\mathrm{BaBi}_{2} \mathrm{Ta}_{2} \mathrm{O}_{9}$ thin film is fairly smooth, and no cracks are formed. The average surface roughness of this film is calculated to be less than $10 \mathrm{~nm}$.

The dielectric properties of $\mathrm{BaBi}_{2} \mathrm{Ta}_{2} \mathrm{O}_{9}$ thin films were measured. Fig. 3 shows the dielectric constant and the dissipation factor as a function of frequency for the $0.4-\mu \mathrm{m}$ thick $\mathrm{BaBi}_{2} \mathrm{Ta}_{2} \mathrm{O}_{9}$ thin film with $\mathrm{Pt} / \mathrm{BaBi}_{2} \mathrm{Ta}_{2} \mathrm{O}_{9} / \mathrm{Pt}$ structure. The measuring frequency ranges from $100 \mathrm{~Hz}$ to $4 \mathrm{MHz}$. The dielectric constant and dissipation factor at $10 \mathrm{kHz}$ are 97.7 and 0.0257 , respectively. Within the low frequency range, the dissipation factor is close to zero, which is undetectable. With an increase in frequency, the dissipation factor slightly rises, indicating that the conductivity of the films is increased with the measuring frequency.

The polarization-electric field curves of $\mathrm{BaBi}_{2} \mathrm{Ta}_{2} \mathrm{O}_{9}$ thin films annealed at 700 and $750^{\circ} \mathrm{C}$ are shown in Fig. 4. Hysteresis measurements were conducted under the operating voltage of $5 \mathrm{~V}$, and the corresponding electrical field is $125 \mathrm{kV} / \mathrm{cm}$. For

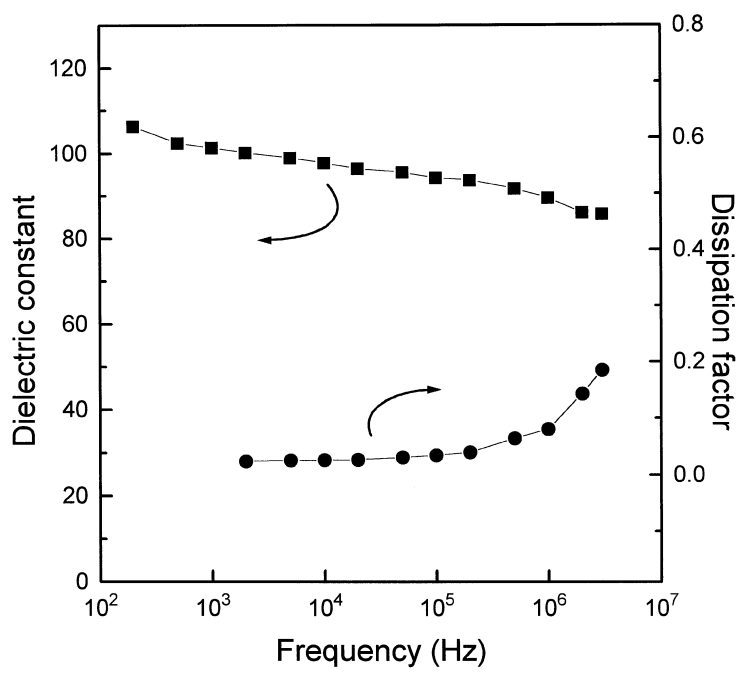

Fig. 3. Plots of dielectric constant and dissipation factor of $\mathrm{BaBi}_{2} \mathrm{Ta}_{2} \mathrm{O}_{9}$ thin films as a function of measuring frequency.

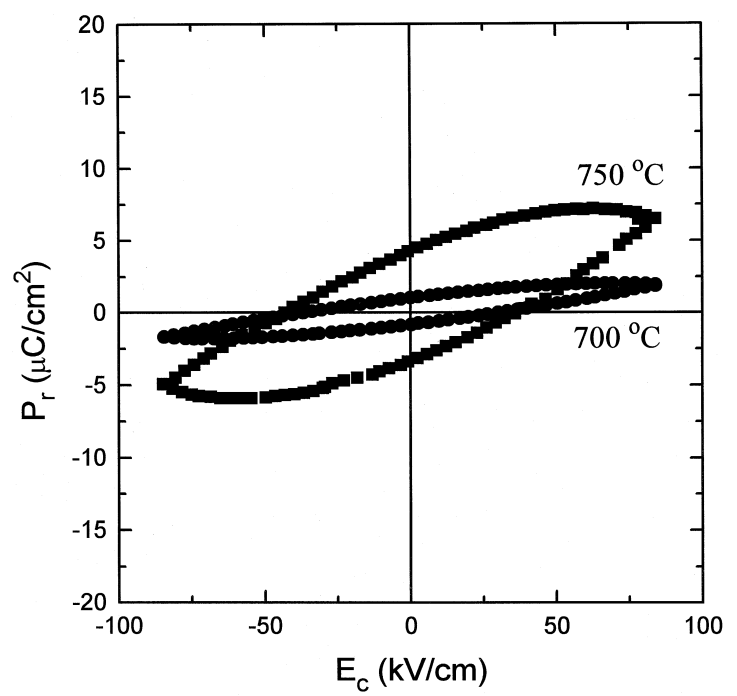

Fig. 4. Polarization electric field hysteresis curves of annealed $\mathrm{BaBi}_{2} \mathrm{Ta}_{2} \mathrm{O}_{9}$ thin films.

$\mathrm{BaBi}_{2} \mathrm{Ta}_{2} \mathrm{O}_{9}$ thin film annealed at $700^{\circ} \mathrm{C}$, the remnant polarization $\left(2 P_{\mathrm{r}}\right)$ and the coercive filed $\left(2 E_{\mathrm{c}}\right)$ are around $2 \mu \mathrm{C} / \mathrm{cm}^{2}$ and $60 \mathrm{kV} / \mathrm{cm}$, respectively. However, for the film annealed at $750^{\circ} \mathrm{C}$, the remnant polarization $\left(2 P_{\mathrm{r}}\right)$ and the coercive filed $\left(2 E_{\mathrm{c}}\right)$ are raised to $8 \mu \mathrm{C} / \mathrm{cm}^{2}$ and $75 \mathrm{kV} / \mathrm{cm}$. From the $P-E$ curves, it is confirmed in this study that

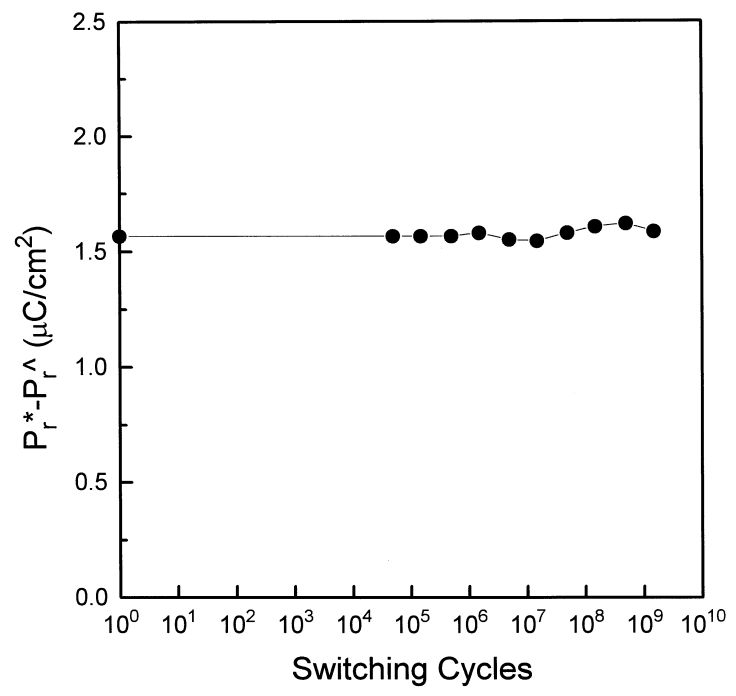

Fig. 5. Polarization fatigue endurance test for $\mathrm{Pt} / \mathrm{BaBi}_{2} \mathrm{Ta}_{2} \mathrm{O}_{9} / \mathrm{Pt}$ capacitors under 8.6- $\mu$ s wide bipolar pulses of $5 \mathrm{~V}$ amplitude. 
$\mathrm{BaBi}_{2} \mathrm{Ta}_{2} \mathrm{O}_{9}$ thin films exhibit ferroelectric properties. Since the Curie temperature of $\mathrm{BaBi}_{2} \mathrm{Ta}_{2} \mathrm{O}_{9}$ is $110^{\circ} \mathrm{C}$ [11], it is reasonable to predict that $\mathrm{BaBi}_{2} \mathrm{Ta}_{2} \mathrm{O}_{9}$ exhibits ferroelectric properties at room temperature.

The fatigue endurance of $\mathrm{BaBi}_{2} \mathrm{Ta}_{2} \mathrm{O}_{9}$ thin film capacitor as a function of switching cycles was examined by applying 8.6- $\mu$ s wide bipolar pulses of $5 \mathrm{~V}$ amplitude, and the results are shown in Fig. 5. $P_{\mathrm{r}} *$ and $P_{\mathrm{r}} \wedge$ represent the values of the switched and non-switched remnant polarization, respectively. The value of $P_{\mathrm{r}} *-P_{\mathrm{r}}$ is approximately corresponding to the value of $2 P_{\mathrm{r}}$. Because the $750^{\circ} \mathrm{C}$-annealed films contain a tiny amount of an unknown phase, only the pure $\mathrm{BaBi}_{2} \mathrm{Ta}_{2} \mathrm{O}_{9}$ films annealed at $700^{\circ} \mathrm{C}$ were examined. It is found that the value of $P_{\mathrm{r}} *-$ $P_{\mathrm{r}} \wedge$ does not decay after $10^{9}$ switching cycles, indicating that $\mathrm{BaBi}_{2} \mathrm{Ta}_{2} \mathrm{O}_{9}$ thin films are near fatiguefree. As mentioned previously, $\mathrm{Pb}(\mathrm{Zr}, \mathrm{Ti}) \mathrm{O}_{3}$-based ferroelectric thin films suffer a serious fatigue problem when fabricated on metal electrodes. However, this study shows that $\mathrm{BaBi}_{2} \mathrm{Ta}_{2} \mathrm{O}_{9}$ thin films deposited on metal electrodes have good polarization endurance as $\mathrm{SrBi}_{2} \mathrm{Ta}_{2} \mathrm{O}_{9}$ thin films do. Because of its high fatigue-resistance, $\mathrm{BaBi}_{2} \mathrm{Ta}_{2} \mathrm{O}_{9}$ is found in this study to be a potential material for the applications of ferroelectric random access memories.

\section{Conclusion}

(i) $\mathrm{BaBi}_{2} \mathrm{Ta}_{2} \mathrm{O}_{9}$ thin films were successfully synthesized on $\mathrm{Pt} / \mathrm{Ti} / \mathrm{SiO}_{2} / \mathrm{Si}$ substrates with the metalorganic decomposition method. Well-crystallized $\mathrm{BaBi}_{2} \mathrm{Ta}_{2} \mathrm{O}_{9}$ thin films were obtained after $700^{\circ} \mathrm{C}$ annealing. (ii) The grains in the $700^{\circ} \mathrm{C}$-annealed $\mathrm{BaBi}_{2} \mathrm{Ta}_{2} \mathrm{O}_{9}$ films had a small grain size (around $10 \mathrm{~nm}$ ) with a spherical shape. In addition, the surface of the prepared films was rather dense and smooth with no cracks.

(iii) The dielectric constant and dissipation factor of $\mathrm{BaBi}_{2} \mathrm{Ta}_{2} \mathrm{O}_{9}$ films at a frequency of $10 \mathrm{kHz}$ were 97.7 and 0.0257 , respectively. The polarizationelectric field hysteresis loops revealed that $\mathrm{BaBi}_{2} \mathrm{Ta}_{2} \mathrm{O}_{9}$ films exhibited ferroelectric properties, and the loss in the remnant polarization of the films was near zero up to $10^{9}$ switching cycles. According to the above results, $\mathrm{BaBi}_{2} \mathrm{Ta}_{2} \mathrm{O}_{9}$ has been proved to have great potential for the applications of ferroelectric random access memories.

\section{References}

[1] J.F. Scott, C.A. Paz de Araujo, Science 246 (1989) 1400.

[2] T. Mihara, H. Watanabe, C.A. Paz de Araujo, Jpn. J. Appl. Phys. 33 (1994) 5281.

[3] G. Arit, N.A. Pertsev, J. Appl. Phys. 70 (1991) 2283.

[4] J.F. Scott, C.A. Araujo, B.M. Melinik, L.D. McMillan, R. Zuleef, J. Appl. Phys. 70 (1991) 382.

[5] T.C. Chen, C.L. Thio, S.B. Desu, J. Mater. Res. 12 (1997) 2628.

[6] R.E. Jones Jr., P.D. Maniar, R. Moazzami, P. Zurcher, J.Z. Witowski, Y.T. Lii, P. Chu, S.J. Gillespie, Thin Solid films 270 (1995) 584

[7] P.C. Joshi, S.O. Ryu, X. Zhang, S.B. Desu, Appl. Phys. Lett. 70 (1997) 1080.

[8] S.S. Park, C.H. Yang, S.G. Yoon, J.H. Ahn, H.G. Kim, J Electrochem. Soc. 144 (1997) 2855.

[9] R. Dat, J.K. Lee, O. Auciello, A.I. Kingon, Appl. Phys. Lett. 67 (1995) 572

[10] C.A. Paz de Araujo, J.D. Cuchiaro, M.C. Scott, L.D. McMillan, Int. Patent Appl. No. WO93/12542, June 24, 1993.

[11] E.C. Subbarao, J. Phys. Chem. Solids 23 (1962) 665.

[12] C.H. Lu, B.K. Fang, J. Mater. Res. (in press). 